\title{
CFD Evaluation and optimization of the HEMJ Divertor cooling design
}

\author{
M. Zhao, B. Ghidersa, R. Stieglitz
}

\section{Motivation and goal}

- He-cooled divertor with multiple-jet cooling (HEMJ) is optional for EU-DEMO - HEMJ must be able to accommodate at least $10 \mathrm{MW} / \mathrm{m}^{2}$ during normal operation - Evaluation and optimization of the heat transfer in HEMJ divertor cooling system - CFD can optimize the cooling design and give a clear view of jet impinging

\subsection{Parameters in simulation of HEMJ divertor}

\begin{tabular}{|c|c|c|c|c|}
\hline & $\begin{array}{c}\text { Pressure } \\
(\mathrm{MPa})\end{array}$ & $\begin{array}{c}\text { Mass flow } \\
(\mathrm{g} / \mathrm{s})\end{array}$ & $\begin{array}{c}\text { Inlet temperature } \\
(\mathrm{C})\end{array}$ & $\begin{array}{c}\text { Target heat flux } \\
\left(\mathrm{MW} / \mathrm{m}^{2}\right)\end{array}$ \\
\hline Helium Flow & 10 & 3.35 & 500 & 10 \\
\hline
\end{tabular}

\subsection{Geometry and parameters of HEMJ divertor}
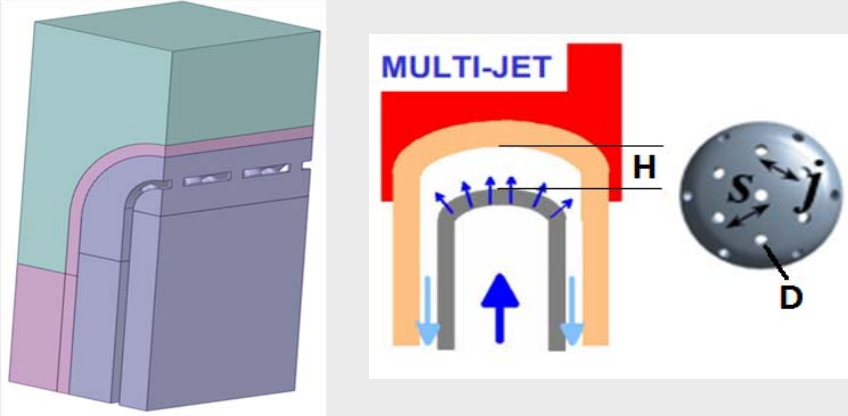

- Heat transfer is very sensitive to Jet Array Parameterization - Projected row (s/D, j/D), jet-to-wall distance $(H)$, jet diameter $(D)$ are expected to be evaluated and optimized.

In the present article, H/D was optimized

\subsection{Mesh and turbulent models}

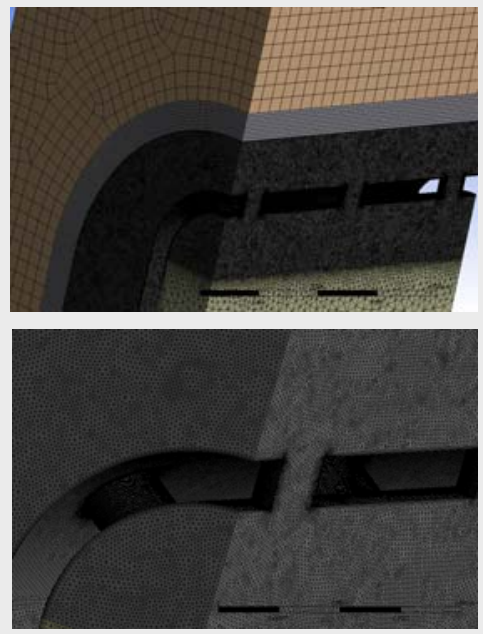

ANSYS V19.2 Meshing and CFX 3.8 Million Mesh in fluid center SST turbulent model $y+$ close to 1

Fluid \& solid properties based on ITER material properties handbook

\section{Evaluation of HEMJ Divertor cooling system}
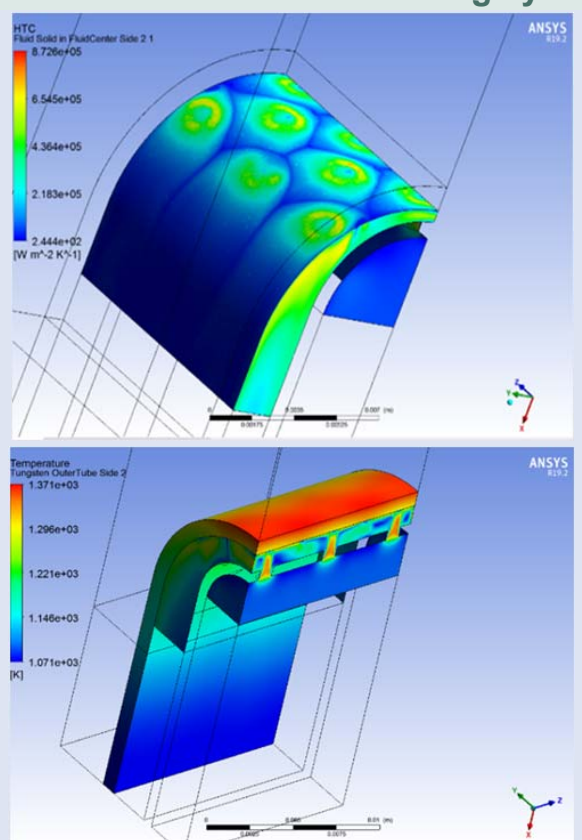

Max local HTC can reach to $872.6 \mathrm{kw} / \mathrm{m}^{2} . \mathrm{K}$ at the projection center and max temperature of tungsten tube is $1371 \mathrm{~K}$.

- Spent helium flow from the neighboring leads to cross flow between impinging jets

\section{Optimization of HEMJ Divertor cooling design}

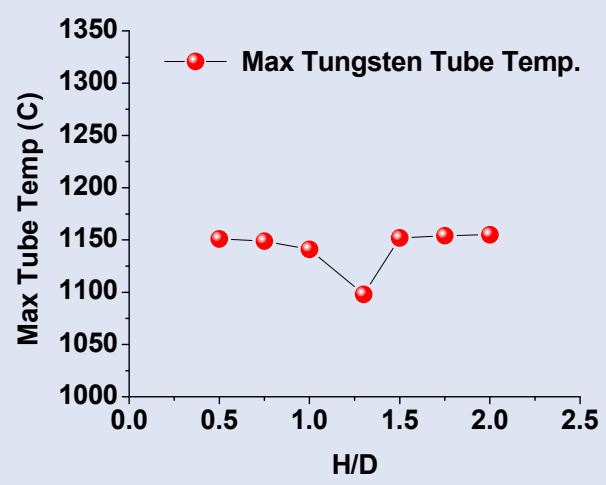

D/D ratio strongly affects the local heat transfer

$\mathrm{H} / \mathrm{D}=1.3$ is the best cooling ability or the minimum surface temperature

\section{Conclusions}

Thermal-hydraulic studies of HEMJ divertor have been performed - H/D was optimized and best cooling ability or the minimum surface temperature at $H / D=1.3$

Max local HTC at the projection center and spent helium flow leads to strongly cross flow

\section{Outlooks}

1) Further works of optimizing jet arrangement, e.g. hexagonal versus in-line, equal jet diameter versus unequal nozzles

2) Comparison between experiment results and CFD simulations 